\title{
POSTHUMANISMO E HIBRIDACIÓN
}

\author{
LUCA VALERA, JOSÉ TOMÁS ALVARADO MARAMBIO \\ Instituto de Filosofía, Centro de Bioética, \\ Pontificia Universidad Católica de Chile
}

\begin{abstract}
RESUMEN: Ha sido usual criticar el posthumanismo por ser una especulación puramente hipotética sin conexión con nuestras posibilidades técnicas y científicas. Se argumenta aquí, sin embargo, que los desarrollos recientes para la producción de diferentes tipos de híbridos - como híbridos de cerdohombre - abren posibilidades reales para el programa posthumanista. El posthumanismo debe ser tomado en serio. En este trabajo presentamos las líneas centrales de la ontología y la ética posthumanistas, y también algunas razones para resistir su programa de transformación social y política.
\end{abstract}

PALABRAS CLAVE: Posthumanismo; hibridación; ontología de los procesos; extensionismo ético.

\section{Posthumanism and Hybridization}

ABSTRACT: It has been usual to criticize Posthumanism for being a purely hypothetical speculation with no connection with our technological and scientific possibilities. It is argued here, nonetheless, that recent developments for the production of different kinds of hybrids - like pig-human hybridsopen real possibilities for the Posthumanist program. Posthumanism should be taken seriously. In this work, we present the main lines of Posthumanist ontology and ethics, and also some reasons to resist its program for social and political transformation.

KEY WORDS: Posthumanism; Hybridization; Ontology of Processes; Moral Extensionism.

\section{Post-humanismo: ¿CIEncia ficción o REALIDAd?}

«Por ese motivo Matrix fue rediseñada así, en el apogeo de su civilización. Ha oído bien: su civilización, porque cuando empezamos a pensar por ustedes, en realidad se convirtió en nuestra civilización y claro, como imaginará es de lo que va todo esto. De evolución, Morfeo. Evolución. Como el dinosaurio. Mire por esa ventana. Su época ya pasó. El futuro es nuestro mundo, Morfeo. El futuro es nuestra época» ${ }^{1}$.

Es notorio que las obras de ciencia ficción muchas veces han adelantado los descubrimientos de la ciencia «normal», abriendo la posibilidad de nuevos paradigmas de interpretación de la realidad. Los ejemplos de Frankenstein de Shelley, el Mundo feliz de Huxley, así como de la Trilogía de la Fundación de Asimov, son bien conocidos y han abierto muchas preguntas acerca del futuro de la humanidad, de nuestra relación con los desarrollos tecnológicos y de la forma de gestionar el poder que estos medios nos entregan. En ese sentido, la imaginación humana, que se expresa a través de la ciencia ficción, tiene un fondo de verdad cuando muestra al ser humano cómo podría ser su futuro, en el momento en que se radicalizarían algunas tendencias y posibilidades actuales. USA 1999.

1 Dialogo presente en la película The Matrix, de Lana Wachowski y Lilly Wachowski, 
Uno de los escenarios posibles para la humanidad futura es, muy claramente, la superación del ser humano mismo, tal cómo se ha desarrollado en su historia, con sus características, calidades y límites. En el pensamiento actual, dicha forma de repensar al ser humano ha sido muy a menudo identificada con los nombres de «trans-humanismo" y "post-humanismo», donde los prefijos «trans-» y "post-» expresan muy claramente la necesidad de superar una realidad que parece obsoleta, para utilizar la famosa imagen de Gunther Anders (2011). Dicha superación, contrariamente a lo que pasa con las otras especies, se caracteriza como una «evolución autodirigida» (Campa, 2010), es decir: «Los humanos son la primera especie que se hará a sí misma obsoleta, mientras que otras especies llegarán a ser obsoletas ya sea debido al desastre ambiental o debido a la competencia entre especies» (Lestel, 2012, 264-5).

A través de la tecnología - y no solamente por la tecnología- el ser humano tiene el poder de auto-superarse, a saber, de volver a su propia especie inadaptada para habitar este mundo y, por eso, requerida de ser reemplazada por otra especie ${ }^{2}$.

Los dos nombres («transhumanismo» y "posthumanismo») que se utilizan para describir dicho proceso de superación, de hecho, aunque usualmente se consideran con el mismo sentido, expresan por lo menos dos momentos distintos en ese proceso, si no dos «seres distintos», como muestra Birnbacher $(2008,95)$ :

«El 'transhumanismo' se puede definir como un movimiento que quiere que nos pongamos en camino hacia la 'posthumanidad', a ir más allá de la humanidad en su forma actual. Los transhumanistas quieren que iniciemos un proceso que finalmente conduzca a la 'posthumanidad', intentando, ahora y en un futuro próximo, trascender ciertos límites inherentes a la condición humana tal como la conocemos».

La principal forma para superar los límites inherentes de la naturaleza humana parece ser justamente el medio tecnológico. De hecho, los transhumanistas enfatizan la necesidad de lograr dicha superación a través del desarrollo tecnológico. En cambio, el punto focal del posthumanismo consiste no tanto en la aceptación acrítica de las posibilidades ofrecidas por la tecnología — tal como sucede con el transhumanismo - sino más bien en una contaminación e hibridación total de los seres humanos con otros seres vivos y con las máquinas. El cambio ofrecido por esta corriente de pensamiento querría configurarse primero como un cambio de paradigma en el pensar acerca del ser humano. Igual que algunas tendencias en la filosofía de la ecología, el posthumanismo propone, para obtener la contaminación total, una eliminación y fluidificación de los límites que impiden la apertura del hombre a la alteridad, negando así también su identidad y, con ella, paradójicamente, la posibilidad misma de la apertura.

\section{AVANCES RECIENTES EN LA HIBRIDACiÓN DE ESPECIES}

Ha sido frecuente criticar las posiciones posthumanistas por estar desconectadas de nuestras posibilidades técnicas efectivas. Se trataría de una reflexión acerca

\footnotetext{
2 Para dar a entender una nueva fase en la historia (no)humana, el símbolo del transhumanismo es $\mathrm{H}+$, (H-plus).
} 
de escenarios puramente hipotéticos. Estaría al mismo nivel que las reflexiones filosóficas que uno pudiese hacer acerca de, por ejemplo, máquinas en el tiempo, o razas de alienígenas que invaden la tierra o infecciones que producen zombis. Se va a mostrar en esta sección, sin embargo, que hay una serie de resultados experimentales que van desde el trabajo de Almeida-Porada (2007) a los recientes resultados de Wu (2017) que han ido haciendo cada vez más verosímil la posibilidad de generar híbridos de diferentes especies, incluyendo la especie humana. Las ideas posthumanistas, entonces, no son meros experimentos mentales. Al perfilarse la posibilidad técnica de realizar la difuminación de fronteras entre el hombre y su ambiente, así como entre lo vivo y lo que no lo es, el posthumanismo se presenta como un programa de acción política, jurídica y ética que reclama una toma de posición reflexiva.

En los experimentos realizados por el equipo dirigido por Wu (2017; Reardon, 2017) se han conseguido híbridos de ratón-rata y de cerdo-hombre —con diferentes grados de éxito, tal como se explicará. Un híbrido ratón-rata ha llegado a desarrollarse como un ratón maduro, viviendo dos años. Estos resultados han estado precedidos por varios pasos previos que han ido preparándolos. El año 2007 tuvo bastante notoriedad la creación de un híbrido oveja-hombre (Almeida-Porada, 2007), aunque se trataba de un resultado de alcances bastante limitados. Lo que el equipo dirigido por Graça Almeida-Porada de la Universidad de Nevada hizo fue incorporar células madre humanas a tejidos hematopoyéticos de una oveja. Se trató de un ejercicio semejante al que se realiza cuando se trasplantan células madre de un ser humano a otro para mejorar problemas en la producción de sangre. Un antecedente mucho más relevante fue el obtenido por el equipo israelita dirigido por Ohad Gafni (2013). Se desarrolló una técnica para obtener células madre aislándolas de la masa celular interior de un blastocito y mantenerlas en una configuración semejante a la de la masa celular interior mediante una estimulación apropiada. Esta técnica fue probada primero en ratones, pero luego se aplicó a células madre humanas. Una de las formas en que la «calidad» de las células madre obtenidas se probó es por su aptitud para integrarse en blastocitos de ratón que luego fueron implantados. Se reportó que las células madre humanas mostraron «integración robusta en la masa de células interiores de ratón»(Gafni, 2013, 285). Se dejó que estos embriones híbridos creciesen 7 u 8 días implantados en un ratón antes de ser disectados. Se obtuvieron quimeras con células humanas integradas en diferentes etapas del desarrollo embrionario y en diferentes locaciones, incluyendo los tejidos cráneofaciales y neuronales. El equipo de Thorold Theunissen (2014; 2016) ha tratado de replicar estos híbridos ratón-hombre inyectando células madre humanas en mórulas y blastocitos de ratón, pero con resultados que muestran muy poca eficiencia en la incorporación funcional en embriones. Estas dificultades son de esperar cuando se trata de generar híbridos entre especies evolutivamente lejanas tal como el ratón y el hombre.

En los experimentos más recientes reportados por Wu et al. (2017), sin embargo, se ha dado un paso importante para la hibridación inter-especies. Se han generado, en primer lugar, híbridos ratón-rata tanto con células madre naive como con células madre mediadas por CRISPR/Cas9. La técnica del CRISPR/cas9 es un mecanismo de edición genética desarrollado a partir de las respuestas inmunológicas de bacterias ante las infecciones virales. Permite seleccionar secuencias precisas del genoma, 
cortarlas y sustituirlas por otras. Esta técnica ya ha sido probada con éxito en embriones humanos por dos equipos de investigadores chinos (Liang, 2015; Kang, 2016). En los experimentos reportados por Wu (2017) se han modificado las células madre de ratones para inhibir las secuencias de su genoma que se expresan, por ejemplo, en el páncreas, el corazón o los ojos. Al inyectar células madre de rata en el blastocito de ratón se ha conseguido no sólo que estas se incorporen en la masa celular, sino que también que se desarrollen precisamente para complementar las partes inhibidas del genoma de ratón. Es especialmente de notar que una diferencia anatómica entre los ratones y las ratas es que las ratas carecen de vesícula. Se encontró, sin embargo, que había células de rata en la vesícula de los híbridos ratón-rata. Uno de estos híbridos vivió dos años como un ratón normal.

El siguiente paso dado por el equipo dirigido por Jun Wu fue generar híbridos entre especies evolutivamente más distantes como son los ungulados ${ }^{3} \mathrm{y}$ los roedores, o los ungulados y los hombres. En el primer caso, se trató de generar híbridos de cerdo-rata sin resultados positivos utilizando células madre de roedores naive - esto es, sin haber sido sometidos a la técnica del CRISPR/Cas9. En el segundo caso, se experimentó sistemáticamente con diferentes tipos de células madre humanas para generar híbridos de cerdo-hombre y de vaca-hombre. En ambos casos se consiguieron resultados positivos en la incorporación de las células madre humanas en blastocitos pre-implantación. Para evaluar el éxito en la incorporación de células humanas en un embrión post-implantación, los cerdos ofrecen muchas más ventajas por su cercanía en anatomía, tamaño y fisiología con los órganos humanos. Se dejaron crecer los embriones hasta el día 21 a 28. La mitad de los embriones híbridos implantados mostraron retardo en su crecimiento. Se hallaron diferencias entre los diferentes tipos de células madre humanas para incorporarse en los tejidos de cerdo y, en general, un nivel de incorporación mucho menor que el de las células de rata en un ratón. Los autores apuntan, sin embargo, que

«los procedimientos y observaciones reportadas aquí acerca de la capacidad de células madre humanas pluri-potenciales para integrarse y diferenciarse en un embrión ungulado - aunque en un nivel y eficiencia bajos - una vez optimizados, podrían constituir un primer paso para la realización del potencial de complementación de blastocitos inter-especies con hPSCs [human pluripotent stell cells: células madre pluripotenciales humanas]» (Wu, 2017, 483-4).

Se ha reportado que el equipo de Hiromitsu Nakauchi de la Universidad de Stanford está tratando de generar híbridos hombre-oveja con la misma técnica (Reardon, 2017), aunque no hay todavía resultados publicados acerca de estos híbridos.

Estos resultados experimentales están todavía lejos de ofrecer un mecanismo técnicamente eficiente y confiable para producir híbridos, pero se trata de antecedentes que apuntan claramente a una línea de desarrollo que perfectamente podría conducir a tales hibridaciones. Por supuesto, uno no puede atribuir a estos equipos de investigación la pretensión de realizar un programa ético-político posthumanista. Las finalidades declaradas tienen que ver con la pretensión de comprender mejor la embriogénesis, desarrollar plataformas de testeo de

3 Los ungulados son mamíferos como los cerdos, las vacas o las ovejas. 
medicamentos en animales «humanizados» y desarrollar órganos y tejidos trasplantables en humanos (Wu, 2017, 484). Es claro, sin embargo, que estos mismos desarrollos técnicos podrían ser puestos al servicio de tal programa posthumanista.

\section{LA HIBRIDACIÓN Y LA ONTOLOGÍA POSTHUMANISTA}

Si, como hemos adelantado, la propuesta teórica posthumanista se diferencia de la transhumanista por el hecho de que la primera hace más hincapié en el fin de la superación del ser humano (la hibridación), mientras que la segunda destaca más los medios de dicha impresa (la tecnología) (Ferrando, 2013, 26-7), será importante analizar en que consiste dicho fin.

En ese sentido, parece que la idea posthumanista es la de ir más allá de los límites humanos, sobrepasando la idea tradicional de forma (Valera, 2016, 107) y, con ella, la de un ser "ontológicamente cerrado», definido y definible (Valera, 2014, 483-6). En palabras de Lepage (2008, 143): «La forma humana pierde sus bordes, su unicidad y se abre a la hibridación y a una ontología compartida: se convierte en un cyborg posthumano». Como destacan los más importantes pensadores posthumanistas —entre ellos Rosi Braidotti- frente a una evidente crisis actual del modelo occidental de ser humano (el tan criticado modelo «antropocéntrico»), es importante, entonces, proponer otro modelo, que pueda superar las dificultades del «viejo» modelo: «Una vez que la centralidad del anthropos es puesta en cuestión, un número de bordes entre el "hombre" y sus otros van cayendo, en un efecto de cascada que abre perspectivas no sospechadas» (Braidotti, 2013, 191).

Surge así el tema de la hibridación posthumanista. La superación del ser humano y de todo lo que consideramos «indeseado» e «innecesario en la naturaleza humana» (Postigo, 2009, 267) deviene alcanzable a través de la hibridación del ser humano con los otros seres vivos y no-vivos, obtenida por medio de los avances tecnológicos actuales. Dicho proceso de hibridación abre la posibilidad de un mundo nuevo (Park, 2015, 113), en el que «el ser humano cruza los bordes existentes entre lo humano y lo no-humano, entre lo vivo y lo no-vivo, y así va más allá de los límites conceptuales de ser-humano al hibridarse con extensiones no-humanas» (Park, 2015, 113-4).

Si el objetivo del posthumanismo es crear una síntesis entre elementos distintos ${ }^{4}$ que, por ende, tienen que unificarse en un solo ente, la primera finalidad de dicho proceso será eliminar la identidad de los elementos a sintetizar, o, a lo mejor, de hacer fluidos los límites de esos elementos. Marchesini $(2016,162)$ describe dicho proceso de «fluidificación» de los contornos orgánicos (e inorgánicos) del siguiente modo:

«La alteridad es de este modo simultáneamente externa e interna a la identidad, por lo que es al mismo tiempo dialéctica e integrada. Este es ciertamente el punto de quiebre entre una aproximación humanística a la identidad humana, que purga la alteridad no-humana, y una aproximación post-humanista integrativa de estas mismas cosas».

4 «Distintos» en dos sentidos: en el sentido de diferentes en cuanto a individualidad y en el sentido de pertenecientes a distintos dominios del mundo viviente y no-viviente. 
Y agrega Pepperell $(2005,10)$ en el Manifiesto Posthumanista: «No hay nada externo a lo humano, porque la extensión de un humano no puede ser fijada». La deconstrucción de la humanidad empieza, entonces, con la deconstrucción de los límites humanos (Valera, 2015, 1457-9), es decir, con la destrucción de los «muros» que definen el habitar/demorar humano: «El borde de un organismo, esto es, del cuerpo, no es una pared de un agente relativamente independiente, sino que es realmente fluido y ambiguo, presto a ser hibridado con otros» (Park, 2015, 118).

Si la alteridad debe "contaminar» el «yo», este último — de hecho- no debe tener paredes o muros que lo definan para que se pueda pensar como un ser totalmente abierto. De este modo «lo humano asume los contornos de una dimensión integrativa, es el resultado de procesos de hibridación, cada vez más abierto a hibridaciones y pierde el sentido de emanación del hombre» (Marchesini, 2016, 165).

El «nuevo» ser, obtenido a través de la hibridación entre el ser humano y «la alteridad no-humana» (Marchesini, 2007, 54), no se podrá, de esta manera, definir con las mismas palabras que utilizábamos antes («hombre», «ser humano», «miembro de la especie homo sapiens sapiens», "persona humana», "sujeto humano», «individuo humano», etc.) porque ya se trata de alguien/algo ${ }^{5}$ que va más allá de la especie humana. Aún más, el posthumanismo quiere repensar todas las categorías tradicionales, planteando nuevas formas de entender e interpretar la realidad: «El posthumanismo muestra la radical incompletitud de lo humano, marcando así un rechazo a considerar la distinción entre "humano" y "nohumano" como dada, y a fundar análisis en este conjunto de categorías presunta e inherentemente fijadas» (Iovino, 2016, 13).

Una de las razones que impide cualquier definición de este «nuevo ser»es, entonces, la eliminación de la identidad: alguien/algo que no es idéntico a sí mismo es difícilmente definible, porque viene a faltar la condición de permanencia del mismo ser en el tiempo. El ser posthumano es un ser que es caracterizado por una condición «no fija» y continuamente «mutable» (Park, 2015, 112), y, por eso, es indefinible (etimológicamente: no tiene finis, del latín «límites»). Por esta razón, el ser "posthumano» es un ser con una «subjetividad post-identitaria, no-unitaria y transversal, basada en relaciones con otros humanos y no-humanos» (Braidotti, 2013, 197). Braidotti $(2016,99)$ luego afirma:

«Defino al sujeto crítico posthumano en el marco de una eco-filosofía de múltiples pertenencias, como un sujeto relacional constituido en y por la multiplicidad, esto es, un sujeto que trabaja a través de las diferencias y que es también internamente diferenciado, pero todavía fundado y responsable (accountable). La subjetividad posthumana es nómada y expresa una forma de responsabilidad corporeizada, insertada en un todo (embedded) y por tanto parcial, basada en un fuerte sentido de colectividad, relacionalidad y por ello de construcción de comunidad».

5 La dificultad de darle una connotación adecuada al «nuevo ser» depende, claramente, del grado de hibridación del ser humano con los otros seres no-humanos (vivos y no-vivos) y, por ende, de la subjetividad que manifestará dicho ser — claramente, no se trata de un mero cálculo matemático (o de porcentuales), sino que de una reflexión ontológica que tenemos que desarrollar, una vez que existan efectivamente dichos seres posthumanos. 
La idea de la no-identidad del ser humano ${ }^{6}$ - así como de todos los seres vivos, y de los organismos en general- necesita de una nueva "ontología», que sepa justificar la primacía del devenir sobre la substancia, de los procesos sobre los entes, de las relaciones sobre los individuos. Por ese motivo, Park $(2015,126)$ utiliza la categoría de «evento» para caracterizar al ser humano:

«Un ser humano no es un objeto o una sustancia consistente de materia elemental, sino un evento (o eventos). Los bordes del ser-humano han sido alterados y expandidos de manera creciente con el desarrollo de las civilizaciones. Así, Bruno Latour dice que debemos sacar lo humano de la injusticia del humanismo y "relocalizar lo humano", pues el límite entre lo humano y lo no-humano está "atrasado" para designar la emergencia de un nuevo humano "en el paso, en el envío, en el continuo intercambio de formas"».

En un mundo de eventos, nuestra mirada está direccionada más bien sobre los hechos, es decir, sobre los acontecimientos, y no tanto sobre las substancias (sujetos, entidades, con sus propias historias) que permitan dichos acontecimientos, con el fin de encontrar algo que permanezca más allá del momento determinado. Tal visión del mundo lleva consigo una ontología que Braidotti $(2006,199)$ llama «ontología de los procesos»: "He argumentado [...] que la teoría posthumana descansa en una ontología de procesos que cuestiona la tradicional ecuación de subjetividad y conciencia racional, resistiendo la reducción de ambas a objetividad y linealidad» (Braidotti, 2013, 196).

La idea de que la realidad, efectivamente, no consiste de substancias, sino que primariamente de relaciones no es nueva (Valera y Tambone, 2014), y ha permeado la reflexión de otras disciplinas, como se puede apreciar en algunas tendencias en la filosofía de la ecología. Pues, como afirma Warwick Fox $(1984,196)$, fundador de la «ecología transpersonal»:

«[La ecología profunda] es la idea de que no podemos establecer divisiones ontológicas firmes en el campo de la existencia, que no hay bifurcación en la realidad entre el dominio de lo humano y de lo no-humano [...] En tanto percibamos límites, habremos fallado en conseguir una conciencia ecológica profunda».

En este sentido la categoría de límite es de fundamental importancia, ya que demarca y define a la entidad misma, permitiendo a la vez las relaciones entre

6 No todos los partidarios de esta tendencia cultural están de acuerdo sobre este último aspecto. Algunos pensadores posthumanistas piensan que se puede hablar de identidad a partir de un proceso de deconstrucción y, por ende, de reconstrucción del «yo»: «El posthumanismo es así un pensamiento que rebalsa con alteridades, puesto que admite alteridades no-humanas e igualmente considera a las alteridades no-humanas como co-factoriales en la creación de la dimensión humana. En la concepción posthumanista, la dimensión humana se considera como una estructura de identidad construida y percibida por medio de la relación con las alteridades no-humanas, así es que estas deben ser consideradas entidades referenciales. La alteridad es un referente capaz de colocarse a sí misma en relación con el proceso de identidad y de tomar parte en él, como formación y como percepción de la identidad, por medio de un input referencial, una verdadera contribución evolucionaria. En la concepción posthumanista, entonces, lo humano no es más la emanación o la expresión del hombre, sino el resultado de la hibridación del hombre con las alteridades no-humanas. Esto significa que lo humano excede las características del hombre» (MARCHESINI, 2016, 166). 
diferentes entidades. De hecho —es importante destacarlo— no hay relaciones sin individuos, y los individuos llevan consigo una propia identidad e historia: la relación (el yo/tú, por ejemplo) es siempre un accidente, y por eso necesita de la substancia (del yo, y del tú). Retomando una vez más la ecología profunda: «Si los fenómenos relacionados entre sí carecen de sustancia, de esencia, o de propia existencia, como sugiere la fórmula budista nihsvabhavam sarvaì dharmam, no hay una última brecha ontológica entre el yo y el no-yo, entre la humanidad y la naturaleza» (Næss, 1997).

Es bien interesante este vínculo entre posthumanismo y ecología profunda (o transpersonal), ya que «el futuro de la humanidad radica en la ecología, en la sustentabilidad o en lo que Braidotti llama [...] convertirse en Tierra» (Herbrechter, 2013 , 9). En este sentido, la ontología de los procesos de Braidotti, que tiene una clara inspiración deleuziana (Braidotti, 2006, 200), constituye la base para una clara ética -así como en la ecología profunda los principios éticos se deducen lógicamente de los postulados ontológicos ${ }^{7}$ - en la que el «principio de hibridación» constituye uno de los fundamentos principales.

\section{UN DEBER MORAL}

Si el programa «ontológico» que sustenta el posthumanismo es la ontología de los procesos, el programa "ético» es el "extensionismo moral» ${ }^{8}$ (Cuomo, 1998, 110; Valera \& Tambone, 2014, 360). Así como explican Henderson \& Waterstone $(2009,93)$ muy eficazmente, una nueva consideración de las entidades conlleva una exigencia de consideración ética extendida:

«Estos problemas se alivian considerablemente cuando ya no somos capaces de postular nuestras identidades (nuestra subjetividad o nuestro yo) aisladas de las redes en las que estamos siempre introducidos. Así como siempre estamos definidos relacionalmente por la interacción con otras personas, estamos materialmente (corpóreamente) inmersos en las complicadas relaciones que forman la biosfera. Comprender la naturaleza siempre actual de estas relaciones nos obliga a pensar de manera diversa y permite la extensión de la consideración moral a otros organismos y a la "naturaleza" inanimada».

Si lo que constituye a todas las entidades, finalmente, son exclusivamente las relaciones que se generan en un ambiente dado, y la «identidad — si así se puede llamar- es algo siempre mutable y vinculada a estas relaciones, hay efectivamente que valorar dichas relaciones. El extensionismo ético (o moral) surge, así, como corolario del "extensionismo ontológico" y de una visión del ser (humano y no-humano), sin identidad, sin lugar y, por eso, nómade. Se trata, efectivamente, de la idea desarrollada por la misma Braidotti $(2006,207)$, que relaciona posthumanismo y ecología:

«Para llegar allí, una posición de sujeto nómade de flujo [...] es un facilitador importante. No se trata de un salto de fe, sino de una transposición activa, una

\footnotetext{
7 Véase, por ejemplo, DeLuca, 2005 y: Næss, 2005, 527.

8 Algunos autores sostienen que exista también un extensionismo "epistemológico» y «ontológico», que corresponde a la mirada que supera la distinción entre distintos (y discernibles) «objetos», que resultarían como algo ficticio o irreal (Pepperell, 2005).
} 
transformación a nivel profundo, un cambio de cultura similar a las mutaciones genéticas, pero también a nivel ético. En este proyecto, los cyborgs y los sujetos nómades son compañeros de especies que perduran».

El ser sin identidad es, al mismo tiempo, un ser sin raíces, ya que no encuentra ninguna radicación en ningún ambiente, viviendo en la «biosfera» de los procesos que cambian. Una vez que se haya vaciado de contenido la identidad, eliminando los límites constitutivos de cada ser, no será difícil reconocer el extensionismo moral como una teoría ética adecuada a la nueva visión del mundo y la creación de nuevas "comunidades morales» (Cuomo, 1998, 42) que no considera como «normativa» la pertenencia a una especie dada. No se trata, por un lado, de algo nuevo, ya que la idea de la extensión de la consideración moral —es decir, derechos y, en algunos casos, deberes- a seres vivos no pertenecientes a la especie humana ha sido desarrollada, entre otros, por Aldo Leopold (1949) en el ámbito de ética ambiental con la famosa Land Ethic, y por Peter Singer (1975) y Tom Regan (1983) en el ámbito de ética animal a través de la lucha al especismo. Por otro lado, sin embargo, se trata de algo verdaderamente novedoso: la extensión moral no se cumple solamente a través de la inclusión ideal de algunos seres en una comunidad dada (la comunidad biótica o la comunidad de los seres sintientes, o la de los sujetos de una vida, para utilizar expresiones de los tres autores recién mencionados), sino que, a través de una inclusión material en el cuerpo del ser mismo, a través de un proceso de hibridación.

Muy claramente, dicha hibridación puede desarrollarse de muchas maneras, y con muchos seres, vivos y no vivos, como están mostrando los procesos tecnológicos actuales. Como es sabido, el proceso de hibridación hombre/máquina tiene ya una historia bastante consolidada, de ciencia ficción o de ciencia normal, tanto que se puede considerar un «símbolo» de la edad tecnológica actual: «La hibridación de los humanos y las máquinas ha llegado a ser un símbolo de una nueva fase de nuestra civilización que descubrirá un aspecto oculto del ser-humano» (Park, 2015, 111).

Una nueva fase se está abriendo a través de una hibridación real entre seres humanos y otros seres vivos, insertándose en el mismo marco teórico de la precedente hibridación. Que el otro «sujeto» de la hibridación sea un ser vivo o un medio tecnológico, poco cambia, en efecto, a nivel teórico (Valera, 2014, 486-9). Lo que sí es importante - y crea una cierta «inquietud» a nivel moral- es la idea de que el ser humano pueda superar sus límites ontológicos para llegar a ser un ser posthumano.

\section{LO MONSTRUOSO}

El «extensionismo moral» es entendido por los posthumanistas como requiriendo la hibridación de lo humano con otros seres vivos y también con lo no-vivo. El híbrido sería la forma de aquello a lo que debería conducirnos nuestra deriva humana. No se trata de una nueva forma de «humanidad», por supuesto, sino de su supresión. Es curioso constatar, sin embargo, que este ideal de destrucción de fronteras, límites y bordes de lo humano y no-humano no es realmente una novedad en la historia de nuestra cultura. Lo que ha resultado nuevo aquí, si se quiere, es la apertura de nuevas posibilidades técnicas — tales como las indicadas 
arriba. El híbrido ha recibido un nombre con anterioridad: es el «monstruo». En su origen, la expresión latina monstrum tenía una connotación religiosa. Se trataba de un portento o suceso extraordinario que anuncia una desgracia o un $\mathrm{mal}^{9}$. El nacimiento de un ser vivo gravemente deforme era usualmente tomado como una advertencia divina, un "mal augurio» y, por esto, se ha denominado después como monstrum a un ser vivo con grave deformidad. Derivativamente, algo «monstruoso» es una persona, ser vivo o acontecimiento que presenta esta falta de armonía y medida. Lo monstruoso genera una reacción que es al mismo tiempo de extrañeza y de temor. Un sinónimo latino de monstrum es portentum, esto es, algo que llama la atención por su diferencia, por contrastar con lo que sería esperable y «normal». Pero algo que resulta inesperado, diferente de lo usual, puede tener un carácter benéfico. También resulta extraño y sorprendente un miraculum, que tiene que ver con una intervención de la divinidad que rompe las regularidades usuales, pero no es algo que produzca una reacción emocional de temor e inquietud. Un miraculum es un bien sorprendente que es signo también de la benevolencia divina. Un monstrum es un signo, pero de algo siniestro e inquietante, de un mal cercano o inminente del que debemos guardarnos.

El programa posthumanista de difuminación de límites y bordes parece un programa para el advenimiento de lo monstruoso. Es curioso constatar que los teóricos post-humanistas han estado conscientes de ello. Lestel, en especial, ha sido un teórico que ha puesto de relieve estas conexiones. La cercanía del posthumanismo con esta tradición, lejos de ser un motivo para distanciarse de las connotaciones más preocupantes del programa ético-político posthumanista son para Lestel un motivo para abrazar la idea de lo monstruoso como algo bienvenido: «Amamos los monstruos no sólo por el hecho de que somos monstruos darwinianos, sino también porque la monstruosidad es nuestro futuro y porque nosotros estamos simplemente condenados a amar a los monstruos» (Lestel, 2012, 267).

De acuerdo a Lestel somos monstruos y nuestro futuro son entidades que habrán de ser monstruosos respecto de nosotros. En efecto, desde la perspectiva darwiniana, todas las especies actualmente existentes de seres vivos han llegado a subsistir porque en algún momento en el pasado se han producido mutaciones que han resultado útiles para mejorar la aptitud para la supervivencia. Respecto de los restantes miembros de su especie, un mutante es algo sorprendente, inesperado, extraño. Las mutaciones que son el mecanismo básico de la deriva evolucionaria de la que provienen todas las especies existentes, es un mecanismo generador de monstruos. De acuerdo al punto de vista darwinista, nosotros mismos, entonces, somos monstruos, cuya monstruosidad resulta ahora oculta y «normalizada». Cada ser viviente es realmente un monstruo. Y el mismo mecanismo de deriva evolucionaria que explica por qué ahora el planeta está poblado de mamíferos en vez de dinosaurios necesariamente habrá de conducir a nuevos monstruos que nos van a sustituir. Nuestro pasado es lo monstruoso. Nuestro destino es lo monstruoso.

Lestel $(2012,266)$ diferencia cuatro fases principales en que la idea de lo «monstruoso» ha sido tratada en Occidente:

9 Cicerón lo enuncia así en el De divinatione: quia ostendunt, portendunt, monstrant, praedicunt, ostenta, portenta, monstra, prodigia dicuntur $(1,42,93)$. Cf. LEWIS \& SHORT, A Latin Dictionary, s. v. 
«La historia de la monstruosidad ha florecido en Occidente a través de cuatro fases principales [...]: 1) los monstruos darwinianos, 2) los monstruos biológicos creados por la tecnología (Pasífae), 3) los monstruos creados con la tecnología (Frankenstein) y 4) los monstruos que hibridan lo viviente con el artefacto y que fuerzan a la creación y a la producción a converger».

Si se recuerda, Pasífae es la ninfa esposa del rey Minos de Creta. El rey Minos se niega a ofrecer a Poseidón un toro blanco, por lo que Poseidón —en castigo— hizo que Pasífae se enamorase de ese toro. El fruto de su unión bestial es el Minotauro. Un ejemplo muy pertinente de híbrido, pero también de monstruo. Pero no es necesario ir a la mitología clásica para hallar estos arquetipos de lo monstruoso, como bien recuerda Lestel. La imagen del engendro del Doctor Frankenstein lleva ya más de un siglo como parte del repertorio tópico en nuestra literatura y nuestro cine. Tal como las viejas mitologías que eran tema una y otra vez de las tragedias, Frankenstein sigue siendo el tema, una y otra vez, de obras cinematográficas. La persistencia cultural de estos motivos es la persistencia de una actitud humana frente a lo monstruoso. Ni el Minotauro ni Frankenstein son ejemplos de híbridos felices. En ambos casos nuestra reacción frente al híbrido es la extrañeza, la sorpresa y el temor. En el caso de Frankenstein, además, el temor se une a la compasión, pues el monstruo también se muestra monstruoso para sí mismo.

La respuesta posthumanista a estas inquietudes es que la actitud de sorpresa, extrañeza y temor se explican por la ignorancia. Se trataría de una reacción de cautela frente a algo nuevo, pero de ningún modo sería una actitud sana que debamos cultivar. El temor frente a lo monstruoso es análogo al temor que pueda tener alguien a que se le aplique una inyección. Es una reacción instintiva que un sujeto racional debe poder controlar, si es que está suficientemente ilustrado acerca de los beneficios de la medicina moderna. Nos parece, sin embargo, que aquí la irracionalidad no está en quienes ven con inquietud el programa ético-político del post-humanismo, sino en quienes parecen depositar una confianza ciega en lo monstruoso como fruto del "progreso».

No se requiere una reflexión muy extensa para percatarse que mutaciones aleatorias o hibridaciones aleatorias serán en su gran mayoría no beneficiosas. Y no lo serán no porque traigan consigo algo nuevo, extraño y que difumina los límites y bordes de lo humano con lo no-humano. La desmesura, la falta de armonía, la monstruosidad del monstruo, no tienen que ver simplemente con su novedad. La monstruosidad resulta inquietante porque es la marca de lo inadecuado, esto es, de lo que no puede insertarse armoniosamente en el plexo de relaciones de la naturaleza humana y no-humana. Un animal monstruoso está abocado a su propia destrucción. Las mismas consideraciones que muestran la importancia de las relaciones entre los diferentes elementos o constituyentes de un ecosistema para conformar y mantener su equilibrio - tan caras a la ecología profunda- son las que hacen también razonable la actitud de temor frente a lo monstruoso. Lo monstruoso es lo que rompe ese equilibrio. La desmesura del monstruo lo hace inadaptado.

El programa ético-político posthumanista se muestra, finalmente, atravesado de una paradoja profunda. Por un lado, parece motivado por la conciencia acerca de una ontología relacional de lo vivo y de lo humano, que se resiste a ver al hombre como un átomo desconectado de la naturaleza completa. Por otro lado, sin embargo, lo que el posthumanista propone como recomendado por esta conciencia 
es un programa de hibridación que sólo se puede llevar adelante con profundo desprecio de esa misma ontología relacional. Supone que cualquier rotura del equilibrio natural será adecuada para este programa. Supone que el delicado plexo de relaciones que sostienen lo viviente son arbitrarias y pueden ser rehechas de cualquier modo. Es paradójico, en efecto, constatar, que las mismas preocupaciones que han estado a la base de lo planteado por muchos teóricos posthumanistas debería llevarlos a una cautela mucho más honda respecto de su propio programa.

\section{BiBLIOGRAFÍA}

Almeida-Porada, G., Porada, C., et al. (2007). «The Human-Sheep Chimeras as a Model for Human Stem Cell Mobilization and Evaluation of Hematopoietic Graft's Potential», en: Experimental Hematology, 35, 1594-600.

Anders, G. (2011). La obsolescencia del hombre (Voll. 1-2), Pre-Textos, Valencia.

Birnbacher, D. (2008). «Posthumanity, Transhumanism and Human Nature», en: Gordjin, B., Chadwick, R. (eds.), Medical Enhancement and Posthumanity. New York: Springer, pp. 95-106.

Braidotti, R. (2006). «Posthuman, All too Human: Towards a New Process Ontology», en: Theory, Culture \& Society, 23/7-8, 197-208.

Braidotti, R. (2013) «Yes, there is no Crisis. Working Towards the Posthumanities», en: International Journal for History, Culture and Modernity, 1/2, 187-99.

Baidotti, R., Veronese, C. (2016). «Can the Humanities Become Post-human? Interview with Rosi Braidotti», en: Relations. Beyond Anthropocentrism, 4/1, 97-101.

Campa, R. (2010). Mutare o perire: la sfida del transumanesimo. Bergamo: Sestante.

Cuomo, C. J. (1998). Feminism and Ecological Communities: An Ethic of Flourishing. London \& New York: Routdlegde.

DeLuca, K. M. (2005). «Thinking with Heidegger: Rethinking Environmental Theory and Practice», en: Ethics \& the Environment, 10/1, 67-87.

Ferrando, F. (2013). «Posthumanism, Transhumanism, Antihumanism, Metahumanism, and New Materialisms. Differences and Relations», en: Existenz, 8/2, 26-32.

Fox, W. (1984). «Deep Ecology: A New Philosophy of our Time?», en: The Ecologist, 14/5-6, 194-200.

Gafni, O., Weinberger, L. et al. (2013). «Derivation of Novel Human Ground State Naive Pluripotent Stem Cells», en: Nature, 504, 282-6.

Henderson, G., Waterstone, M. (2009) "Making Justice Spatial», en: Henderson, G., Waterstone, M. (eds.), Geographic Thought A praxis perspective. London \& New York: Routledge, pp. 91-4.

Herbrechter, S. (2013). «R. Braidotti. The Posthuman. Cambridge: Polity Press. Review», en: Culture Machine, 1-13.

Iovino, S. (2016). "Posthumanism in Literature and Ecocriticism. Introduction», en: Relations. Beyond Anthropocentrism, 4/1, 11-20.

Kang, X., He, W., et al. (2016). «Introducing Precise Genetic Modifications into Human 3PN Embryos by CRISPR/Cas-Mediated Genome Editing», en: Journal of Assisted Reproductive Genetics 33, 581-8.

Leopold, A. (1949). A Sand Country Almanac and Sketches Here and There. New York: Oxford University Press.

Lepage, L. (2008). "Posthuman Perspectives and Postdramatic Theatre: The Theory and Practice of Hybrid Ontology in Katie Mitchell's The Waves», en: Cultura, lenguaje y representación 6, 137-49.

Lestel, D. (2012). «Why Are We So Fond of Monsters?», en: Comparative Critical Studies, 9/3, 259-69. 
Lewis, C. I. (1879). Short, C., A Latin Dictionary. Oxford: Clarendon Press.

Liang, P., Xu, Y., et al. (2015). «CRISPR/Cas9-Mediated Gene Editing in Human Tripronuclear Zygotes», en: Protein Cell, 6, 363-72.

Marchesini, R. (2007). «Ruolo delle alterità nella definizione dei predicati umani», en: Barcellona, P., Ciaramelli, F., Fai, R. (eds.), Apocalisse e post-umano. Il crepuscolo della modernità. Bari: Dedalo, pp. 33-56.

Marchesini, R. (2016). «Nonhuman Alterities», en: Angelaki, 21/1, 161-72.

Næss, A. (1977). «Heidegger, Postmodern Theory and Deep Ecology», en: The Trumpeter. Journal of Ecosophy, 14/4, http://trumpeter.athabascau.ca/index.php/trumpet/article/ view/175/216.

Næss, A. (2005). «Self-Realization: An Ecological Approach to Being in the World», en: Glasser, H., Drengson, A. (eds.), The Selected Works of Arne Ncess. Dordrecht: Springer, vol. X, pp. 515-30.

Park, I. (2015). "Rereading of the Whiteheadian Understanding of Organism in a TransHuman Age: A Critical Review of the "Extended Mind Theory"», en: Trans-Humanities Journal, 8/1, 111-30.

Pepperell, R. (2005). «Posthumans and Extended Experience», en: Journal of Evolution and Technology, 14.

Postigo Solana, E.(2009). "Transumanesimo e postumano: principi teorici e implicazioni bioetiche», en: Medicina e morale, 2, 267-82.

Reardon, S. (2017). «Hybrid Zoo: Introducing Pig-Human Embryos and a Rat-Mouse», en: Nature, doi:10.1038/nature.2017.21378.

Regan, T. (1983). The Case for Animal Rights. Berkeley \& Los Angeles: University of California Press.

Singer, P. (1975). Animal Liberation: A New Ethics for Our Treatment of Animals. New York: Random House.

Theunissen, T.W., Powell, B. E., et al. (2014). «Systematic Identification of Culture Conditions for Induction and Maintenance of Naive Human Pluripotency», en: Cell Stem Cell 15, 471-87.

Theunissen, T.W., Friendli, M., et al. (2016). «Molecular Criteria for Defining the Naive Human Pluripotent State», en: Cell Stem Cell 19, 502-15.

Valera, L. (2014). «Post-Humanism: Still or Beyond Humanism», en: Cuadernos de Bioética, $25 / 3,481-91$.

Valera, L., Tambone, V. (2014). «The Goldfish Syndrome. Human Nature and the Post-human Myth», en: Cuadernos de Bioética, 25/3, 353-66.

Valera, L. (2015). «Tecnologia ed ecologia. Dall'etica alla metafisica, dalla negazione del limite alla negazione dell'uomo», en: Pensamiento, 71/269, 1453-62.

Valera, L. (2016). «Wearable Robots in Rehabilitative Therapy: A Step Towards Transhumanism or an ecological support?», en: Filosofia Unisinos, 17/2, 105-10.

Wu, J., Platero-Luengo, A., et al. (2017). «Interspecies Chimerism with Mammalian Pluripotent Stem Cells», en: Cell, 168, 473-86.

Instituto de Filosofía y Centro de Bioética

LUCA VALERA

Pontificia Universidad Católica de Chile

luvalera@uc.cl

Instituto de Filosofía

Pontificia Universidad Católica de Chile,

jalvaram@uc.cl /jose.tomas.alvarado@gmail.com

José Tomás Alvarado Marambio

[Artículo aprobado para publicación en enero de 2018] 